\title{
PROVENIÊNCIA E AMBIENTAÇÃO TECTÔNICA DE METASSEDIMENTOS DE ALTO GRAU: NAPPE TRÊS PONTAS-VARGINHA, SUL DO CRÁTON SÃO FRANCISCO
}

\author{
MARIA DA GLÓRIA MOTTA GARCIAํㅜ, MÁRIO DA COSTA CAMPOS NETO² \& VALDECIR \\ DE ASSIS JANASI ${ }^{2}$
}

\begin{abstract}
PROVENANCE AND TECTONIC SETTING OF HIGH-GRADE METASEDIMENTS: TRÊS PONTAS-VARGINHA NAPPE, SOUTH OF SÃO FRANCISCO CRATON Samples of granulite- to amphibolite-facies metasedimentary rocks of the Três Pontas-Varginha Nappe, south of São Francisco Craton, were analised. The results indicated that the kyanite-bearing gneisses from the base of the nappe, Três Pontas area, can be divided in two groups with different chemical characteristics. The first one presents high $\mathrm{SiO}_{2} / \mathrm{Al}_{2} \mathrm{O}_{3}$ ratios (3.28-4.69), low $\mathrm{K}_{2} \mathrm{O} / \mathrm{Na}_{2} \mathrm{O}$ (0.45-1.06) ratios, and low IAQ values (48-60). The second group exhibits high and varied $\mathrm{SiO}_{2} / \mathrm{Al}_{2} \mathrm{O}_{3}$ ratios $(2.55-4.71)$ and high $\mathrm{K}_{2} \mathrm{O} / \mathrm{Na}_{2} \mathrm{O}$ ratios $(2.30-11.71)$, probably constituting products of relatively pure pelitic sediments. The ASI values are high (67-79) and suggestive of a long weathering period marked by intense chemical weathering. Passive margin settings or, alternatively, old crustal sources are the most probable origin for these sediments. The upper unit of kyanite/sillimanite-bearing gneisses from the Varginha area are more homogeneous and show high $\mathrm{SiO}_{2} / \mathrm{Al}_{2} \mathrm{O}_{3}$ ratios (3.03-4.59) and relatively low $\mathrm{K}_{2} \mathrm{O} / \mathrm{Na}_{2} \mathrm{O}$ ratios $(0.23-2.48)$, which suggest an origin from feldspar-rich psamitic sediments, probably wackes. The low ASI values (51-65) indicate that rocks from the source area were lesser affected by chemical weathering, suggesting a general prevalence of physical weathering or other short-termed weathering processes. These characteristics are compatible with postArchean active margin settings.
\end{abstract}

Keywords: Brazil, geochemistry, metasediments, Neoproterozoic, provenance

Resumo Foram analisadas amostras de rochas metassedimentares metamorfisadas nas facies granulito a anfibolito alto, pertencentes à Nappe Três Pontas-Varginha, na região a sul do Cráton São Francisco. Os resultados indicaram que os gnaisses com cianita da base da nappe, região de Três Pontas, podem se agrupados em dois conjuntos com características químicas distintas. O primeiro apresenta razões $\mathrm{SiO}_{2} / \mathrm{Al}_{2} \mathrm{O}_{3}$ altas mas pouco variadas $(3,28-4,69)$ e $\mathrm{K}_{2} \mathrm{O} / \mathrm{Na}_{2} \mathrm{O}$ baixas $(0,45-1,06)$, além de baixos valores de IAQ $(48-60)$. O segundo conjunto exibe razões $\mathrm{SiO}_{2} / \mathrm{Al}_{2} \mathrm{O}_{3}$ altas e variadas $(2,55-4,71)$ e $\mathrm{K}_{2} \mathrm{O} / \mathrm{Na}_{2} \mathrm{O}$ altas $(2,30-11,71)$, constituindo prováveis produtos de sedimentos pelíticos relativamente puros. Os valores de IAQ são altos (67-79) e sugestivos de histórias intempéricas prolongadas, marcadas por intenso intemperismo químico. Ambientes de margem passiva ou, alternativamente, fontes crustais antigas, são os mais prováveis para a origem destes sedimentos. Os gnaisses com cianita e sillimanita do topo, região de Varginha, são mais homogêneos e mostram razões $\mathrm{SiO}_{2} / \mathrm{Al}_{2} \mathrm{O}_{3}$ altas $(3,03-4,59)$ e $\mathrm{K}_{2} \mathrm{O} / \mathrm{Na}_{2} \mathrm{O}$ relativamente baixas $(0,23-2,48)$ que sugerem uma origem a partir de sedimentos psamíticos ricos em feldspato, provavelmente wacke. Os baixos valores de IAQ (51-65) indicam que as rochas na área-fonte sofreram histórias intempéricas pouco severas, marcadas por predomínio de intemperismo físico ou por processos intempéricos de curta duração. Estas características os aproximam de ambientes de margens ativas pós-arqueanas.

Palavras-chave: Brasil, geoquímica, metassedimentos, Neoproterozóico, proveniência

INTRODUÇÃO A composição química das rochas sedimentares pode fornecer importantes subsídios para a caracterização de suas fontes, história de intemperismo e ambiente de sedimentação. Estudos acerca do comportamento de elementos maiores mostram que as razões $\mathrm{K}, \mathrm{O} / \mathrm{Na}_{2} \mathrm{O}$ e $\mathrm{Al}_{2} \mathrm{O}_{3} / \mathrm{Na}_{2} \mathrm{O}$ são modificadas pelos processos intempéricos e, portanto, podem ser utilizadas para inferir a natureza e duração dos processos superficiais à época da deposição (McLennan \& Taylor 1991).

Por sua vez, os estudos sobre a proveniência de sedimentos são largamente baseados no comportamento dos elementos terras raras (ETR). Isto porque estes elementos são insolúveis e ocorrem com concentrações muito baixas nas águas do mar e de rios. Os
ETR presentes em um sedimento são, portanto, transportados com as partículas detríticas e refletem a composição química de suas fontes (Rollinson 1995). Adicionalmente, elementos como o Sc e o Th não são muito afetados por diagênese (como Fe, Mn e $\mathrm{Pb}$ ), metamorfismo e fracionamento de minerais pesados (como Zr, $\mathrm{HfeSn}$ ).

O objetivo deste estudo é avaliar a história da sedimentação de rochas metassedimentares metamorfisadas nas facies granulito e anfibolito alto, pertencentes à Nappe Três Pontas-Varginha, no setor a sul do Cráton São Francisco. As modelagens tectônicas, baseadas seja na idade de cristais detríticos de zircão (Söllner \& Trouw 1997), seja na idade de gnaisses tidos como embasamento

I - GEG - Grupo de Estudos em Geodinâmica da UFC, Departamento de Geologia, Universidade Federal do Ceará, 60455-760, Fortaleza, Brasil

2 - Instituto de Geociências, Universidade de São Paulo, 05508-900, São Paulo, Brasil

E-mails: mggarcia@ufc.br, camposnt@usp.br, vajanasi@usp.br 
(Heilbron et al. 1989), consideram o Cráton São Francisco, a norte, como possível fonte dos sedimentos (Trouw et al. 2000). Mais recentemente, dados isotópicos de $\mathrm{Sm}-\mathrm{Nd}$ (Janasi 1999) revelaram valores de T(DM) de 1,4 e 1,55 Ga para cianita granulitos da Nappe Três Pontas-Varginha e 1,2 Ga para granada-biotita-plagioclásio gneisses da Nappe Aiuruoca-Andrelândia, correlata, com $\varepsilon N d$ à época do metamorfismo regional ( 625 Ma) de -3,6 a -2,1 e-1,2, respectibamente. Estes valores foram considerados incompatíveis com uma proveniência do cráton para os sedimentos e sugerem uma contribuição de fonte juvenil com características de margem continental ativa (Janasi et al. 2000). A idade da deposição dos sedimentos com assinatura química de wacke, que afloram na região de Aiuruoca, baseadas em valores U-Pb em zircão detrítico (Campos Neto et al., inédito) encontra-se no Neoproterozóico Criogeniano, em acordo com os dados já obtidos por Machado \& Gauthier (1996), Söllner \& Trouw (1997), Valladares et al. (1999).

Contexto Geológico A área estudada situa-se a sul do Cráton São Francisco (Fig. 1) e faz parte de uma sucessão de nappes neoproterozóicas com deslocamento geral para leste e separadas por rampas laterais sobre as quais evoluíram falhas transcorrentes tardias (Trouw et al. 1986, Campos Neto \& Caby 1999, 2000, Trouw et al.2000). A unidade superior (Nappe Socorro-Guaxupé) constitui um terreno derivado de um arco magmático convergente (Campos Neto \& Figueiredo 1995). Sua porção basal exibe um bandamento tectônico formado por assembléias nas facies granulito e anfibolito, como gnaisses enderbíticos e charnockíticos, granada granulitos, granulitos máficos e quartzo-feldspáticos, além de gnaisses metapelíticos com sillimanita em menor proporção.

A unidade subjacente e da qual provêm as amostras analisadas (Nappe Três Pontas-Varginha) consiste, da base para o topo, de rutilo-granada-cianita granulitos que gradam para sillimanita granulitos com cianita, indicando um padrão metamórfico invertido, observado ao longo de uma pilha com $\mathrm{ca} .5 \mathrm{~km}$ de espessura (Campos Neto \& Caby 1999, Garcia et al. 2003). Ocorrem intercalações de quartzitos e, subordinadamente de gnaisses calciossilicáticos, metabásicas e meta-ultramáficas.

A sequêencia subjacente (Nappe Carmo da Cachoeira) tem

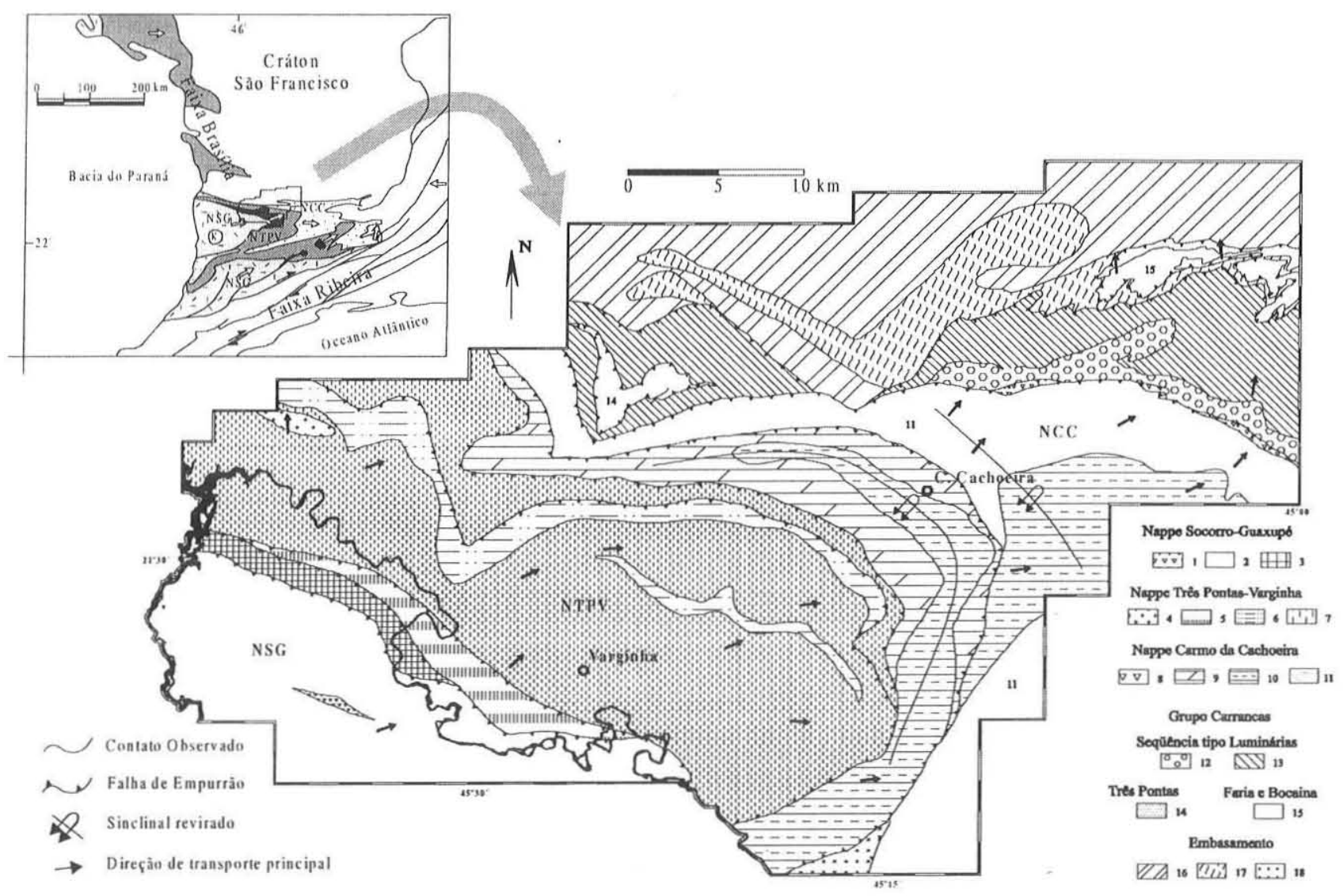

Figura I - Mapa geológico. I. Sillimanita gnaisses; 2. Gnaisses charnoquíticos a enderbíticos, gnaisses tonalíticos e granada granulitos máficos; 3. leucogranito gnáissico; 4. Muscovita-granada granito gnáissico; 5. migmatitos e quartzitos; 6. granadacianita quartzitos; 7. Sillimanita e cianita-granada gnaisses granulíticos (gnaisses calciossilicáticos subordinados); 8. Anfibolitos e granada anfibolitos; 9. Quartzitos, muscovita quartzitos e anfibolitos; 10. Cianita-granada-biotita-plagioclásio gnaisses; 11. Cianita-granada-mica xistos (gonditos subordinados); 12. Quartzitos e grafita filitos; 13. Filitos; 14. Filitos acinzentados e quartzitos finos; 15. Estaurolita-cloritóide-clorita-muscovita xistos e quartzitos finos; 16.Granodiorito gnaisses; 17. Seqüência máfico-ultramáfica; 18. ortognaisses miloníticos. Localização geológica segundo Campos Neto \& Caby (2000). Regiões das Serras de Três Pontas (14) e Faria/Bocaina compiladas e simplificadas de Maciel (1986) e Chrispin (1990), respectivamente. 
aproximadamente $3 \mathrm{~km}$ de espessura de metapelitos com cianita e granada, gnaisses, rochas metabásicas e gonditos. O contato basal é uma superfície de empurrão caracterizada por um pulo metamórfico sobre unidades quartzíticas, a leste, e sobre ortognaisses granodioríticos e rochas ultramáficas pertencentes a infraestrutura da Nappe Luminárias (Trouw et al. 2000).

Todo sistema de nappes caracteriza-se por trajetórias metamórficas de alta pressão (Trouw \& Castro 1996, Trouw et al. 1998), em um padrão térmico invertido e que registra condições báricas equivalentes ao soterramento da pilha metassedimentar a ca. $60 \mathrm{~km}$ de profundidade (Campos Neto \& Caby 1999, Campos Neto et al. 1999).

\section{AMOSTRAGEM E PROCEDIMENTOSANALÍTICOS Ao} todo foram reunidos dados referentes a 24 amostras de rocha total, 8 das quais retiradas da pesquisa de Janasi (1999). Adicionalmente, a análise de ETR da amostra NESG72y também foi tomada do mesmo autor. Das 16 amostras restantes, 6 foram feitas no Laboratório de Química e Plasma ICP-AES do IG/USP, para as quais foram determinados os valores $\mathrm{de} \mathrm{Fe}^{2+}$ por volumetria, Perda ao Fogo (PF) por gravimetria e os óxidos de elementos maiores, assim como os traços V, Zr, Y, La, Sre Ba por Espectrometria de Emissão em Plasma Indutivamente Acoplado (ICP). Outras 8 amostras foram analisadas no Activation Laboratories (Actlabs) por Ativação Neutrônica (INAA). As 2 amostras restantes foram analisadas por Fluorescência de Raios X no Laboratório de Geoquímica da Universidade de Edinburgh.

As amostras analisadas são gnaisses da Nappe Três PontasVarginha, unidade constituída por cianita-granada gnaisses, que gradacionam a cianita/sillimanita-granada gnaisses no topo e exibem metamorfismo na fácies granulito de alta pressão. Correspondem, respectivamente, aos tipos Três Pontas e Varginha de Campos Neto \& Caby (1999). Para distinção química, ambos tipos foram tratados separadamente, sendo doravante referidos de modo simplificado como Três Pontas e Varginha. Foram investigadas 9 amostras da unidade basal, Três Pontas (NESG72 e RE113, pedreira de Três Pontas) e 15 da unidade superior, Varginha (NESG88 (pedreira de Varginha), VA89, VA206, VA162, VA167e VA73).

Os resultados analíticos constam da Tabela 1 . A normalização dos Elementos Terras Raras (ETR) foi feita pelo condrito de Taylor \& McLennan (1985). Os diagramas multi-elementares foram normalizados ao NASC (North American Shale Composite), de Gromet et al. (1984).

RESULTADOS Elementos maiores Os gnaisses analisados são variáveis composicionalmente, tanto em termos de elementos maiores como traços. Os teores de $\mathrm{SiO}_{2}$ variam de 57 a $72 \%$, enquanto os valores para $\mathrm{Al}_{2} \mathrm{O}_{3}$ situam-se entre 14,2 e $22,7 \%$. As razões $\mathrm{SiO}_{2} / \mathrm{Al}_{2} \mathrm{O}_{3}$ são relativamente altas $(2,55-4,71)$ e homogêneas para os dois tipos de gnaisses, mas as razões $\mathrm{K}_{2} \mathrm{O} / \mathrm{Na}_{2} \mathrm{O}$ são consideravelmente distintas $(0,45-11,71$ para os gnaisses Três Pontas e 0,23-2,48 para as amostras de Varginha). A distribuição destes valores no diagrama $\mathrm{K}_{2} \mathrm{O} / \mathrm{Na}_{2} \mathrm{O} \times \mathrm{SiO}_{2} / \mathrm{Al}_{2} \mathrm{O}_{3}$ (Fig. 2) mostra uma distinção entre os dois tipos, que tendem a plotar, respectivamente, nos campos dos folhelhos e das grauvacas de Wronkiewicz \& Condie (1987).

Para destacar as semelhanças e diferenças entre as rochas estudadas, diagramas bivariantes utilizando um índice empírico de maturidade mineral $\left(\mathrm{IMAT}=\left\{\mathrm{SiO}_{2} /\left(\mathrm{SiO}_{2}+\mathrm{Al}_{2} \mathrm{O}_{3}\right) \times 100\right\}\right.$ proposto por Jost et al. (1996) - foram construídos para elementos maiores e são mostrados na Fig. 3. Nestes diagramas, o comportamento dos óxidos de elementos maiores e traços foi testado e permitiu o monitoramento químico dos tipos de rochas envolvidos. De um modo geral, os gnaisses tipo-Varginha apresentam comportamento mais homogêneo, enquanto que as amostras da região de Três Pontas mostram maior espalhamento. As correlações positivas com $\mathrm{SiO}_{2}$ e negativas com $\mathrm{Al}_{2} \mathrm{O}_{3}$ (Figs. $3 \mathrm{~A} \mathrm{e} 3 \mathrm{C}$ ) são compatíveis com o aumento da quantidade de quartzo na medida em que decresce o conteúdo de minerais micáceos. Os diagramas correspondentes aos óxidos $\mathrm{FeO}+\mathrm{Fe}_{2} \mathrm{O}_{3}, \mathrm{MgO}, \mathrm{MnO}$ e TiO 2 (Figs. 3E, $3 \mathrm{G}, 3 \mathrm{H} \mathrm{e} 3 \mathrm{~J}$ ) exibem correlações negativas, nas quais as amostras de Varginha apresentam geralmente valores intermediários àqueles das amostras de Três Pontas. O restante dos óxidos, $\mathrm{Na}_{2} \mathrm{O}, \mathrm{K}_{2} \mathrm{O}$, $\mathrm{P}_{2} \mathrm{O}_{5}$ e CaO (Figs. 3B, 3D, 3F e 3I) não mostram correlações visíveis. $\mathrm{Na}$ figura 3D, uma amostra (RE113e) apresenta um teor destacado de potássio que provém da grande quantidade de biotita na sua composição modal, fato coerente com seu baixo valor do IMAT. O alto teor de fósforo (Fig. 3F) verificado em outra amostra (RE113f) é devido à maior abundância de apatita.

A variação entre $\mathrm{CaO}, \mathrm{Na}_{2} \mathrm{O}$ e $\mathrm{K}_{2} \mathrm{O}$ foi também testada e os diagramas são mostrados na Fig. 4. Uma correlação positiva configurada principalmente pelas amostras de Varginha, alinhandose segundo uma razão aproximada de 1:1, pode ser observada no diagrama $\mathrm{Na}_{2} \mathrm{O} \times \mathrm{CaO}$ (Fig. 4A). A comparação entre os valores de $\mathrm{K}_{2} \mathrm{O}$ e Na $\mathrm{O}_{2} \mathrm{O}$ permite distinguir dois grupos que se alinham grosso modo segundo uma correlação negativa (Fig. 4B). A relação entre os três óxidos (Fig. 4C) mostra a disposição das amostras segundo uma linha em direção a $\mathrm{K}_{2} \mathrm{O}$, que não distingue, aparentemente, entre os dois tipos de gnaisses. Como já observado, são os conteúdos de $\mathrm{CaO}$ que separam os dois tipos.

Elementos traço Os diagramas multi-elementares construídos para comparar as abundâncias dos elementos traços nas amostras são apresentados na Fig. 5. Na Fig. 5A estão dispostos os valores correspondentes às amostras de Três Pontas. Todas elas apresentam padrões enriquecidos em relação à média utilizada, mas com empobrecimento marcante em Cs. As outras duas

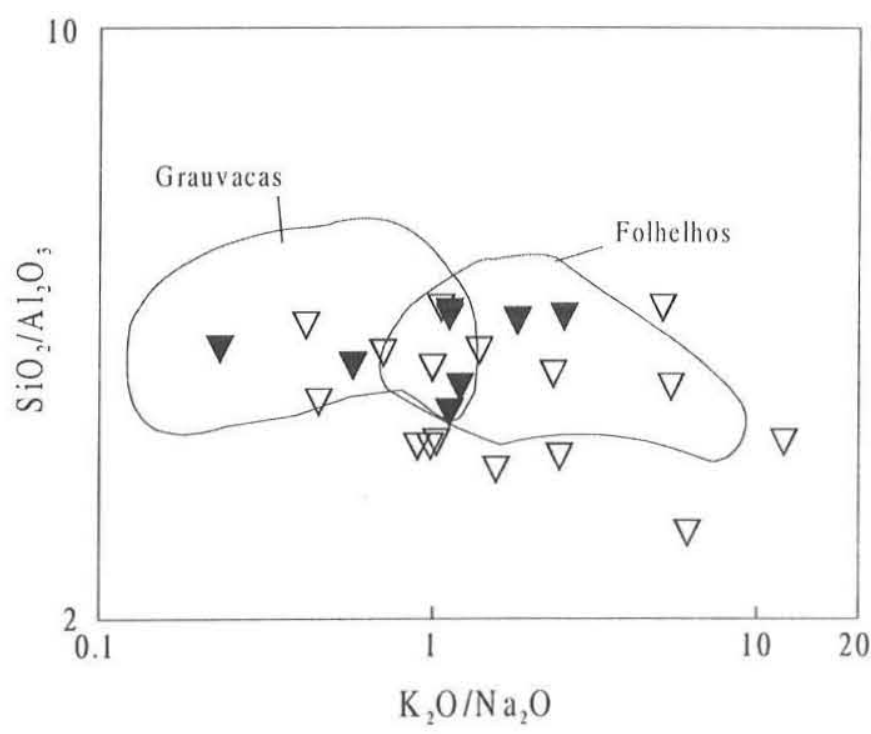

Figura 2-Diagrama $\mathrm{SiO}_{2} \times \mathrm{Al}_{2} \mathrm{O}_{3}$. Delimitação dos campos de grauvacas e folhelhos segundo Wronkiewicz \& Condie (1987). Triângulo vazado: Três Pontas; triângulo cheio: Varginha. 
Tabela 1 - Análises químicas de elementos maiores e traços.

\begin{tabular}{|c|c|c|c|c|c|c|c|c|c|c|c|c|c|}
\hline AMOSTRA & RE113a & RE113c & RE113d & RE113e & RE113f & VA89a & VA89b & VA89d & VA206a & Nesg72y & AMOSTRA & VA162a & VAl67 \\
\hline $\mathrm{SiO}_{2}$ & 64,20 & 62,87 & 72,39 & 57,65 & 72,21 & 63,74 & 70,77 & 57,30 & 57,12 & 58,48 & $\mathrm{SiO}_{2}$ & 59,54 & 64,24 \\
\hline $\mathrm{Al}_{2} \mathrm{O}_{3}$ & 19,64 & 15,12 & 15,44 & 22,65 & 15,33 & 15,96 & 15,73 & 17,78 & 18,25 & 16,08 & $\mathrm{Al}_{2} \mathrm{O}_{3}$ & 16,8 & 15,93 \\
\hline $\mathrm{Fe}_{2} \mathrm{O}_{3}$ & 1,96 & 2,78 & 0,32 & 1,91 & 6,02 & 0,17 & 0,08 & 1,16 & 10,44 & 0,40 & $\mathrm{Fe}_{2} \mathrm{O}_{3}$ & 9,11 & 7,36 \\
\hline $\mathrm{FeO}$ & 8,18 & 7,43 & 0,63 & 7,18 & & 7,21 & 2,16 & 7,54 & & 11,51 & $\mathrm{MgO}$ & 4,17 & 3,08 \\
\hline $\mathrm{MgO}$ & 1,96 & 2,78 & 0,32 & 1,91 & 1,08 & 3,36 & 1,35 & 4,42 & 4,73 & 2,93 & $\mathrm{CaO}$ & 2,55 & 2,84 \\
\hline $\mathrm{CaO}$ & 0,87 & 5,65 & 2,29 & 1,20 & 0,36 & 2,20 & 2,41 & 2,73 & 1,97 & 3,98 & $\mathrm{Na}_{2} \mathrm{O}$ & 2,46 & 2,86 \\
\hline $\mathrm{Na}_{2} \mathrm{O}$ & 0,26 & 2,65 & 3,82 & 1,12 & 0,52 & 2,44 & 3,95 & 2,91 & 1,67 & 2,25 & $\mathrm{~K}_{2} \mathrm{O}$ & 2,73 & 1,64 \\
\hline $\mathrm{K}_{2} \mathrm{O}$ & 3,04 & 1,87 & 4,04 & 6,68 & 2,59 & 2,41 & 1,64 & 2,82 & 4,05 & 1,01 & $\mathrm{P}_{2} \mathrm{O}_{5}$ & 0,22 & 0,21 \\
\hline $\mathrm{P}_{2} \mathrm{O}_{5}$ & 0,33 & 0,09 & 0,02 & 0,03 & 0,12 & 0,06 & 0,04 & 0,17 & 0,12 & 0,59 & $\mathrm{MnO}$ & 0,16 & 0,14 \\
\hline $\mathrm{MnO}$ & 0,09 & 0,14 & 0,01 & 0,12 & 0,09 & 0,16 & 0,04 & 0,19 & 0,20 & 0,24 & $\mathrm{TiO}_{2}$ & 1,00 & 0,91 \\
\hline $\mathrm{TiO}_{2}$ & 1,30 & 1,26 & 0,17 & 1,12 & 1,07 & 0,83 & 0,35 & 1,11 & 1,17 & 1,94 & P.F. & & 0,16 \\
\hline P.F. & $<0,01$ & 0,17 & 0,74 & 0,14 & 0,09 & 0,06 & 1,24 & 0,70 & 0,11 & $<0,01$ & Total & 98,74 & 99,37 \\
\hline Total & 101,83 & 102,81 & 100,21 & 101,72 & 99,47 & 98,61 & 99,76 & 98,84 & 99,61 & 99,41 & V & 178 & 151 \\
\hline V & 141 & 182 & 14 & 110 & 111,5 & 120 & 213 & 44 & 194,1 & 69,46 & $\mathrm{Cr}$ & 216,1 & \\
\hline $\mathrm{Cr}$ & 114 & 10 & 13 & 140 & 99,7 & 107 & 145 & 34 & 141,9 & & $\mathrm{Co}$ & 26,4 & \\
\hline Co & 22 & 24 & 2 & 18 & & 22 & 28 & 7,2 & & & $\mathrm{Ni}$ & 54,7 & \\
\hline $\mathrm{Ni}$ & 52 & 10 & 10 & 52 & 41 & 64 & 93 & 17 & 106,5 & & $\mathrm{Sc}$ & 24,5 & \\
\hline Sc & & & & & 14 & & & & 27,1 & 6,30 & $\mathrm{Cu}$ & & \\
\hline $\mathrm{Cu}$ & 33 & 17 & 10 & 33 & 11,4 & 41 & 12 & 64 & 8 & & $\mathrm{Zn}$ & & \\
\hline $\mathrm{Zn}$ & 90 & 99 & 17 & 63 & 58,8 & 100 & 162 & 34 & 156,9 & & $\mathrm{Ga}$ & 0,56 & \\
\hline Ga & 24 & 20 & 20 & 22 & & 17 & 23 & 17 & & & $\mathrm{Ge}$ & 0,07 & \\
\hline Ge & 2 & 1 & 1 & 2 & & 2 & 2 & 1 & & & $\mathrm{Rb}$ & 70 & \\
\hline As & 5 & 5 & 5 & 5 & & 5 & 5 & 5 & & & $\mathrm{Sr}$ & 230 & 214 \\
\hline $\mathrm{Rb}$ & 124 & 55 & 98 & 183 & 72 & 54 & 104 & 27 & 135 & & $\mathrm{Y}$ & 34,8 & 33 \\
\hline $\mathrm{Sr}$ & 154 & 425 & 929 & 746 & 146,2 & 190 & 218 & 324 & 173 & 429,97 & $\mathrm{Zr}$ & 202 & 193 \\
\hline Y & 36 & 26 & 2 & 39 & 26,1 & 38 & 44 & 11 & 46 & 32,67 & $\mathrm{Nb}$ & 16,9 & \\
\hline Zr & 317 & 128 & 321 & 295 & 234,2 & 223 & 257 & 84 & 254 & 288,70 & Mo & 0,47 & \\
\hline $\mathrm{Nb}$ & 28 & 8 & 3 & 33 & 18,1 & 14 & 13 & 4 & 19,1 & & Cs & 0,52 & \\
\hline Mo & 1 & 0,5 & 0,5 & 0,9 & & 1,3 & 0,6 & 0,5 & & & $\mathrm{Ba}$ & 785 & 444 \\
\hline $\mathrm{Ag}$ & 0,5 & 0,5 & 0,5 & 0,5 & & 0,5 & 0,5 & 0,5 & & & Hf & 4,87 & \\
\hline In & 0,2 & 0,2 & 0,2 & 0,2 & & 0,2 & 0,2 & 0,2 & & & $\mathrm{Ta}$ & 0,78 & \\
\hline Sn & 2 & 1 & 2 & 2 & & 1 & 3 & 1 & & & Th & 4,83 & \\
\hline $\mathrm{Sb}$ & 0,1 & 0,1 & 0,1 & 0,1 & & 0,1 & 0,1 & 0,1 & & & $\mathrm{U}$ & 0,42 & \\
\hline Cs & 0,5 & 0,5 & 0,6 & 0,7 & & 0,5 & 1,5 & 0,5 & & & La & 18,52 & 34 \\
\hline $\mathrm{Ba}$ & 686 & 612 & 1435 & 1847 & 764 & 583 & 840 & 298 & 1162,8 & 522,49 & $\mathrm{Ce}$ & 37,55 & \\
\hline $\mathrm{Hf}$ & 8,4 & 3,4 & 8,4 & 7,7 & & 5,8 & 6,7 & 2,5 & & & $\mathrm{Pr}$ & 5,03 & \\
\hline $\mathrm{Ta}$ & 1,79 & 0,5 & 0,19 & 2,08 & & 0,89 & 0,66 & 0,19 & & & $\mathrm{Nd}$ & 19,89 & \\
\hline W & 0,9 & 0,5 & 0,5 & 0,5 & & 0,5 & 0,5 & 0,5 & & & $\mathrm{Sm}$ & 4,24 & \\
\hline $\mathrm{Tl}$ & 0,5 & 0,3 & 0,5 & 0,7 & & 0,3 & 0,6 & 0,1 & & & Eu & 1 & \\
\hline $\mathrm{Pb}$ & 12 & 18 & 50 & 44 & 8 & 20 & 20 & 20 & 18,6 & & Gd & 4,87 & \\
\hline $\mathrm{Bi}$ & 0,2 & 0,2 & 0,2 & 0,2 & & 0,2 & 0,2 & 0,2 & & & $\mathrm{~Tb}$ & 1,01 & \\
\hline Th & 26 & 8,1 & 3,4 & 2 & 11,4 & 5,8 & 11 & 1,2 & 11,7 & & Dy & 6,55 & \\
\hline U & 1,9 & 1,7 & 0,6 & 0,7 & 1,4 & 0,9 & 1,2 & 0,5 & 2,3 & & Ho & 1,33 & \\
\hline La & 73 & 24 & 16 & 11 & 42 & 22 & 40 & 12 & 31,4 & 49,56 & Ex & 3,44 & \\
\hline $\mathrm{Ce}$ & 149 & 50 & 28 & 19 & 90,3 & 41 & 83 & 21 & 67,2 & 101,38 & $\mathrm{Yb}$ & 3,18 & \\
\hline $\mathrm{Pr}$ & 16,2 & 5,78 & 2,67 & 1,89 & & 4,49 & 9,89 & 2,29 & & 11,80 & Lu & 0,49 & \\
\hline $\mathrm{Nd}$ & 60 & 23 & 9 & 7,2 & 39 & 17 & 40 & 8,3 & 27 & 47,12 & & & \\
\hline $\mathrm{Sm}$ & 11 & 5 & 1,3 & 2,3 & & 3,6 & 8,4 & 1,5 & & 9,73 & & & \\
\hline Eu & 2,16 & 1,51 & 1,36 & 2,59 & & 1,69 & 1,86 & 1,76 & & 2,60 & & & \\
\hline Gd & 9 & 4,5 & 0,6 & 5 & & 5,1 & 7,7 & 1,5 & & 9,22 & & & \\
\hline $\mathrm{Tb}$ & 1,4 & 0,7 & $-0,1$ & 1,2 & & 1,1 & 1,3 & 0,3 & & 1,56 & & & \\
\hline Dy & 7,1 & 4,4 & 0,3 & 7,1 & & 6,5 & 7,4 & 1,9 & & 9,22 & & & \\
\hline Ho & 1,3 & 0,9 & $-0,1$ & 1,4 & & 1,3 & 1,5 & 0,4 & & 1,76 & & & \\
\hline Ex & 3,9 & 2,7 & 0,2 & 3,9 & & 3,9 & 4,5 & 1,2 & & 4,74 & & & \\
\hline $\mathrm{Tm}$ & 0,60 & 0,43 & $-0,05$ & 0,63 & & 0,64 & 0,72 & 0,17 & & & & & \\
\hline $\mathrm{Yb}$ & 3,7 & 2,7 & 0,1 & 4,1 & & 4,1 & 4,7 & 1 & & 4,13 & & & \\
\hline $\mathrm{Lu}$ & 0,54 & 0,39 & $-0,04$ & 0,57 & & 0,59 & 0,66 & 0,17 & & 0,63 & & & \\
\hline
\end{tabular}

amostras (RE113d e RE113e) possuem padrões mais distintos, caracterizados por empobrecimento em Cs, Th, U, ETRL e ETRM, além de ETRP e de elementos ferro-magnesianos na amostra RE113d. Enriquecimentos em Rb, Ba, Sr e Ta (este na amostra RE113e) também são observados. O enriquecimento em Th observado em uma das amostras (RE113a) pode ser devido à presença de monazita, que ocorre com frequiência como importante mineral acessório. Duas das amostras (RE11d e RE113e) apresentam um acentuado enriquecimento em estrôncio, além de teores moderados de potássio e sódio. A Fig. 5B mostra os padrões resultantes da normalização de quatro amostras de Varginha. Um dos exemplares (VA206a) é composicionalmente muito semelhante à média empregada, mas apresenta empobrecimento em Cs e enriquecimento em $\mathrm{Ba}, \mathrm{Sr}, \mathrm{Zr}$ e elementos ferro-magnesianos. As outras amostras (VA89a, VA89b e VA89d) apresentam padrões bastante semelhantes à anterior mas são, nesta ordem, gradualmente mais ricas em todos os elementos considerados.

Embora o Sc tenha sido analisado em apenas 8 das amostras, as 
Tabela I - Análises químicas de elementos maiores e traços. (cont.)

\begin{tabular}{|c|c|c|c|c|c|c|}
\hline AMOSTRA & VA167a & VAl67e & VA73b & VA73f & VA73g & VA73j \\
\hline $\mathrm{SiO}_{2}$ & 62,04 & 65,7 & 67,65 & 66,92 & 66,15 & 67,21 \\
\hline $\mathrm{Al}_{2} \mathrm{O}_{3}$ & 16,39 & 14,32 & 14,89 & 15,91 & 14,21 & 14,63 \\
\hline $\mathrm{Fe}_{2} \mathrm{O}_{3}$ & 8,76 & 7.32 & 5,38 & 4,24 & 7.17 & 6.17 \\
\hline $\mathrm{MgO}$ & 3,93 & 3,05 & 1.64 & 1,22 & 3,15 & 1,65 \\
\hline $\mathrm{CaO}$ & 2,31 & 2,41 & 2,33 & 3,57 & 3,29 & 1,72 \\
\hline $\mathrm{Na}_{2} \mathrm{O}$ & 2,13 & 2,13 & 2,12 & 4,05 & 2,07 & 1,86 \\
\hline $\mathrm{K}_{2} \mathrm{O}$ & 2.56 & 2.38 & 3.78 & 0,93 & 2,32 & 4,62 \\
\hline $\mathrm{P}_{2} \mathrm{O}_{5}$ & 0.19 & 0.15 & 0.04 & 0,06 & 0.19 & 0.19 \\
\hline $\mathrm{MnO}$ & 0.18 & 0.13 & 0.09 & 0.07 & 0.14 & 0,14 \\
\hline $\mathrm{TiO}_{2}$ & 1.04 & 1.03 & 0,67 & 0.55 & 0.98 & 0.86 \\
\hline P.F. & 0,02 & & 0,23 & & 0,41 & \\
\hline Total & 99,55 & 98,62 & 98,82 & 97,52 & 100,08 & 99,05 \\
\hline V & 132 & 135 & 63 & 55 & 124 & 80 \\
\hline Gr & 101,6 & & & 12,7 & & \\
\hline Co & 16,9 & & & 8.7 & & \\
\hline $\mathrm{Ni}$ & 34,9 & & & 10 & & \\
\hline Sc & 14,9 & 18 & 11,9 & 9,4 & 15 & \\
\hline $\mathrm{Cu}$ & 15,7 & & & & & \\
\hline Zn & 93 & 103 & & & 108 & \\
\hline Ga & 1,38 & & & 1,1 & & \\
\hline $\mathrm{Ge}$ & 0,66 & & & 0,11 & & \\
\hline $\mathrm{Rb}$ & 94 & 90 & & 28 & 95 & \\
\hline $\mathrm{Sr}$ & 196 & 166 & 204 & 371 & 207 & 144 \\
\hline Y & 34,1 & 31 & 29 & 15,7 & 26 & 38 \\
\hline $\mathrm{Zr}$ & 214 & 232 & 272 & 173 & 216 & 261 \\
\hline $\mathrm{Nb}$ & 15,5 & 5 & & 5.4 & 5 & \\
\hline Mo & 0.38 & & & 0.42 & & \\
\hline Cs & 0.32 & & & 0,11 & & \\
\hline $\mathrm{Ba}$ & 675 & 640 & 902 & 172 & 584 & 859 \\
\hline $\mathrm{Hf}$ & 6,13 & & 7,2 & 4,64 & & \\
\hline $\mathrm{Ta}$ & 1 & & 0,6 & 0,36 & & \\
\hline Th & 3,76 & 15 & 12,6 & 3,08 & 8 & \\
\hline U & 0,84 & & 1 & 0,22 & & \\
\hline La & 14.15 & 35 & 63.1 & 20,59 & 33 & 61 \\
\hline $\mathrm{Ce}$ & 36,64 & 85 & 74 & 37,72 & 71 & \\
\hline Pr & 4.25 & & & 4,09 & & \\
\hline $\mathrm{Nd}$ & 17,67 & 49 & 27 & 14,36 & 41 & \\
\hline Sm & 4,48 & & 3,66 & 2,59 & & \\
\hline Eu & 1,1 & & 1,72 & 1,07 & & \\
\hline Gd & 5,23 & & & 2,97 & & \\
\hline $\mathrm{Tb}$ & 0,98 & & 0,9 & 0,56 & & \\
\hline Dy & 5,96 & & & 3,16 & & \\
\hline Ho & 1,33 & & & 0,58 & & \\
\hline Ex & 3.65 & & & 1,33 & & \\
\hline $\mathrm{Yb}$ & 3,57 & & 2,8 & 1,04 & & \\
\hline Lu & 0,56 & & 0,43 & 0,15 & & \\
\hline
\end{tabular}

razões Th/Sc obtidas serão reportadas aqui porque constituem-se em indicadores de proveniência de sedimentos (McLennan et al. 1991, 1995). Duas amostras de gnaisses, uma de Três Pontas (RE113f) e outra de Varginha foram analisadas (VA206a), sendo os valores de Th/Sc de 0,814 e 0,43, respectivamente. Segundo Taylor \& McLennan (1985), o valor de Th/Sc da média da crosta superior é 1,0. Valores semelhantes a este são interpretados por McLennan et al. (1991) como compatíveis com uma origem em plataforma relativamente estável para os sedimentos, enquanto valores

\begin{tabular}{lrrrrrr}
\hline AMOSTRA & Nesg88c & Nesg88d & Nesg88g & Nesg72e & Nesg72c & Nesg72o \\
\hline $\mathrm{SiO}_{2}$ & 59,17 & 56,15 & 63,62 & 67,24 & 66,82 & 57,16 \\
$\mathrm{Al}_{2} \mathrm{O}_{3}$ & 18,31 & 18,53 & 15,20 & 17,10 & 17,58 & 17,45 \\
$\mathrm{Fe}_{2} \mathrm{O}_{3}$ & 0,28 & 0,06 & 0,58 & 0,26 & 0,33 & 0,04 \\
$\mathrm{FeO}$ & 7,95 & 10,04 & 6,76 & 8,06 & 7,96 & 11,91 \\
$\mathrm{MgO}$ & 3,75 & 4,93 & 3,62 & 1,38 & 2,14 & 4,20 \\
$\mathrm{CaO}$ & 2,51 & 2,36 & 2,85 & 0,46 & 0,61 & 4,14 \\
$\mathrm{Na} \mathrm{O}_{2} \mathrm{O}$ & 2,83 & 2,07 & 1,99 & 1,27 & 0,63 & 1,50 \\
$\mathrm{~K}_{2} \mathrm{O}$ & 2,54 & 3,22 & 2,73 & 2,93 & 3,35 & 1,53 \\
$\mathrm{P}_{2} \mathrm{O}_{5}$ & 0,11 & 0,14 & 0,15 & 0,09 & 0,10 & 0,15 \\
$\mathrm{MnO}_{\mathrm{TiO}}$ & 0,18 & 0,15 & 0,14 & 0,12 & 0,11 & 0,26 \\
$\mathrm{P.F}$ & 1,11 & 1,20 & 1,04 & 1,52 & 1,29 & 1,94 \\
$\mathrm{Total}_{\mathrm{V}}$ & $<0,01$ & 0,06 & 0,34 & $<0,01$ & $<0,01$ & 0,48 \\
$\mathrm{Sr}$ & 98,73 & 98,91 & 99,03 & 100,43 & 100,93 & 100,75 \\
$\mathrm{Yr}$ & 148,4 & 196,08 & 128,09 & 117,65 & 129,87 & 213,80 \\
$\mathrm{Zr}$ & 263,76 & 204,55 & 225,02 & 147,87 & 131,82 & 222,56 \\
$\mathrm{Ba}$ & 37,49 & 42,78 & 30 & 23,03 & 26,66 & 29,40 \\
& 275,09 & 229,8 & 213,1 & 388,28 & 320,75 & 333,56 \\
& 776,67 & 830,04 & 773,05 & 587,26 & 684,74 & 407,46
\end{tabular}

inferiores seriam consistentes com ambientes de margem ativa.

Elementos Terras Raras Para os Elementos Terras Raras foram analisadas 12 amostras, sendo 5 de cianita gnaisses de Três Pontas e 7 de cianita/sillimanita gnaisses de Varginha. Embora em geral os tipos de padrões obtidos sejam semelhantes para os dois grupos, a distribuição dos ETR está mostrada em figuras distintas, 6A e $6 \mathrm{~B}$, para uma melhor visualização. O padrão mais típico, verificado em 9 das 12 amostras, caracteriza-se por enriquecimento em ETRL $\left(\mathrm{La}_{\mathrm{N}} / \mathrm{Sm}_{\mathrm{N}}=1,99-4,18\right)$, pouco fracionamento dos ETRP $\left(\mathrm{Gd}_{\mathrm{N}} /\right.$ $\left.\mathrm{Yb}_{\mathrm{N}}=1,01-1,97\right)$, conteúdos de ETR variáveis $(\Sigma \mathrm{ETR}=68-340) \mathrm{e}$ anomalias negativas de $\mathrm{Eu}(\mathrm{Eu} / \mathrm{Eu} *=0,66-0,97)$, com exceção da amostra VA89a, que apresenta uma leve anomalia positiva (Eu/ $\left.\mathrm{Eu}^{*}=1,21\right)$. Outra amostra (VA73f) distingue-se pelo maior fracionamento em ETRP $\left(\mathrm{Gd}_{\mathrm{N}} / \mathrm{Yb}_{\mathrm{N}}=2,32\right)$ e nos ETR em geral $\left(\mathrm{La}_{\mathrm{N}} /\right.$ $\left.\mathrm{Yb}_{\mathrm{N}}=13,39\right)$ e pela anomalia levemente positiva de Eu (Eu/ $\left.\mathrm{Eu}^{*}=1,18\right)$.

Duas amostras apresentam padrões bem distintos das demais, RE113d e VA89d, caracterizados por conteúdos bem mais baixos de ETR ( $\Sigma E T R=59,24$ e 53,49), fortes anomalias positivas de Eu $\left(\mathrm{Eu} / \mathrm{Eu}^{*}=4,71\right.$ e 3,59$)$ e um por um fracionamento de ETR que, no caso da amostra RE113d, é extremo $\left(\mathrm{La}_{\mathrm{N}} / \mathrm{Yb}_{\mathrm{N}}=109\right)$.

Avaliação do grau de intemperismo da área-fonte $\mathrm{O}$ grau de intemperismo de áreas-fonte de sedimentos pode ser avaliado utilizando-se o Índice de Alteração Química (IAQ) proposto por Nesbitt \& Young (1982), que utiliza as proporções moleculares dos óxidos de acordo com a seguinte relação:

$$
\mathrm{IAQ}=\left[\mathrm{Al}_{2} \mathrm{O}_{3} /\left(\mathrm{Al}_{2} \mathrm{O}_{3}+\mathrm{CaO} *+\mathrm{Na}_{2} \mathrm{O}+\mathrm{K}_{2} \mathrm{O}\right)\right] \times 100
$$

onde $\mathrm{CaO}^{*}$ é a quantidade de $\mathrm{CaO}$ incorporada na fração silicática da rocha, descontados carbonato e apatita.

Cerca de $63 \%$ das amostras analisadas possuem valores de IAQ entre 55 e $67 ; 19 \%$ têm valores entre 48 e 51 e $25 \%$ apresentam resultados entre 74 e 81 . As amostras de gnaisses tipo-Varginha exibem uma dispersão nos valores (51 a 65, para uma média de 59) bem menor que para os gnaisses tipo-Três Pontas (48 a 79, para uma média de 65). Estes resultados indicam uma predominância de intemperismo físico na área-fonte da maioria destas rochas. A distribuição dos dados no diagrama de proporções moleculares A-CN-K (Fig. 7) é consistente com esta afirmação e mostra que tanto os gnaisses Três Pontas como Varginha alinham-se segundo 

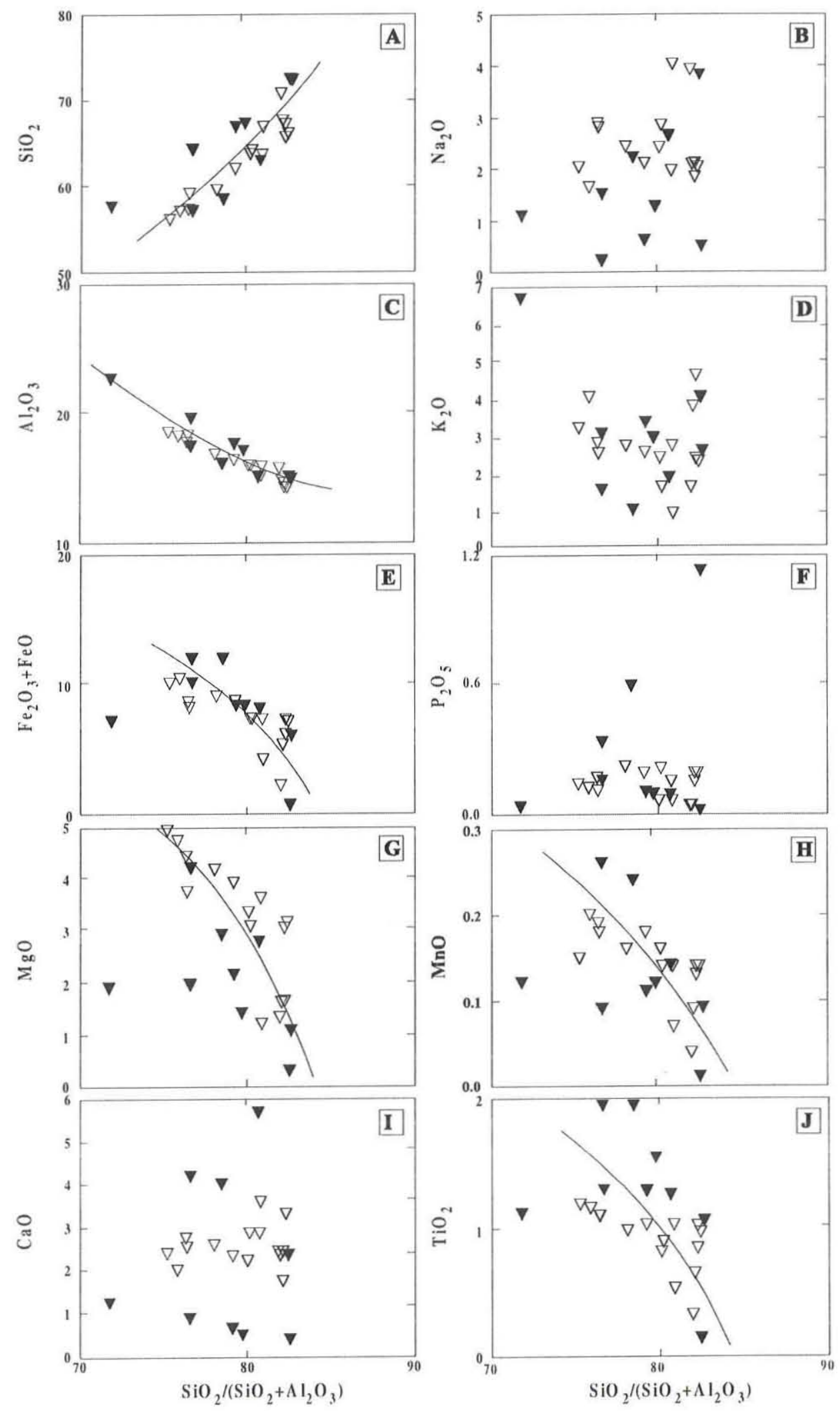

Figura 3 - Diagramas $\mathrm{SiO}_{2} /\left(\mathrm{SiO}_{2}+\mathrm{Al}_{2} \mathrm{O}_{3}\right)-I M A T-x$ óxidos de elementos maiores. Triângulo vazado = Três Pontas; triângulo cheio $=$ Varginha . 

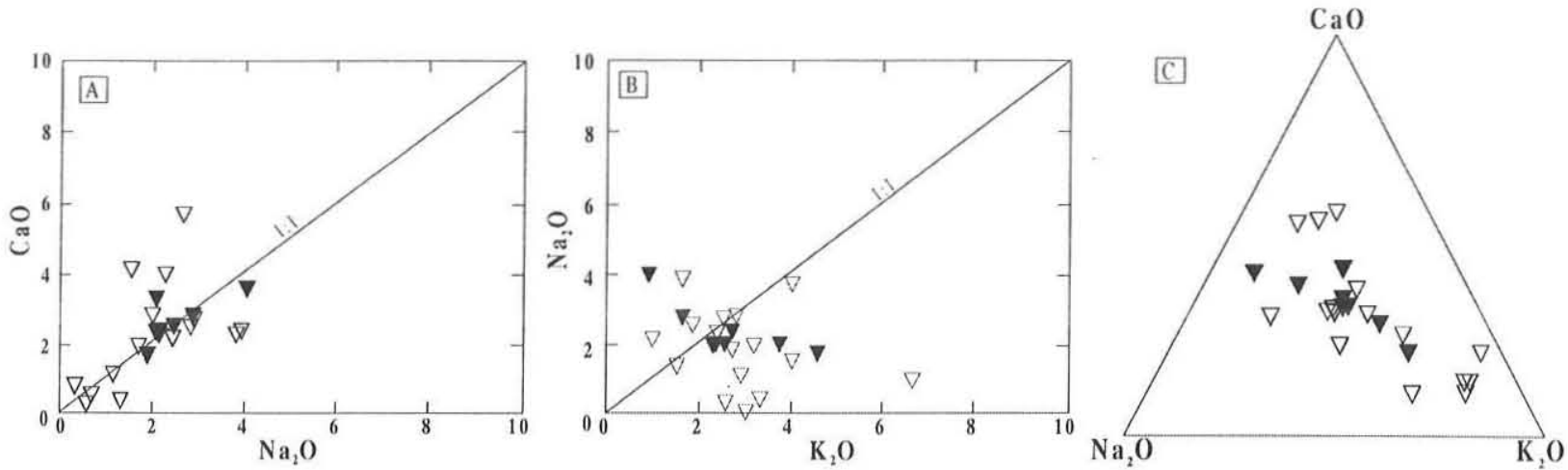

Figura 4 - Diagramas de variação entre $\mathrm{CaO}, \mathrm{Na}_{2} \mathrm{O}$ e $\mathrm{K}_{2} \mathrm{O}$. a) $\mathrm{CaO} \times \mathrm{Na}_{2} \mathrm{O}$; b) $\mathrm{Na}_{2} \mathrm{O} \times \mathrm{K}_{2} \mathrm{O} ; \mathrm{c}$ ) $\mathrm{CaO} \times \mathrm{Na}_{2} \mathrm{O} \times \mathrm{K}_{2} \mathrm{O}$. Triângulo vazado $=$ Três Pontas; triângulo cheio $=$ Varginha .
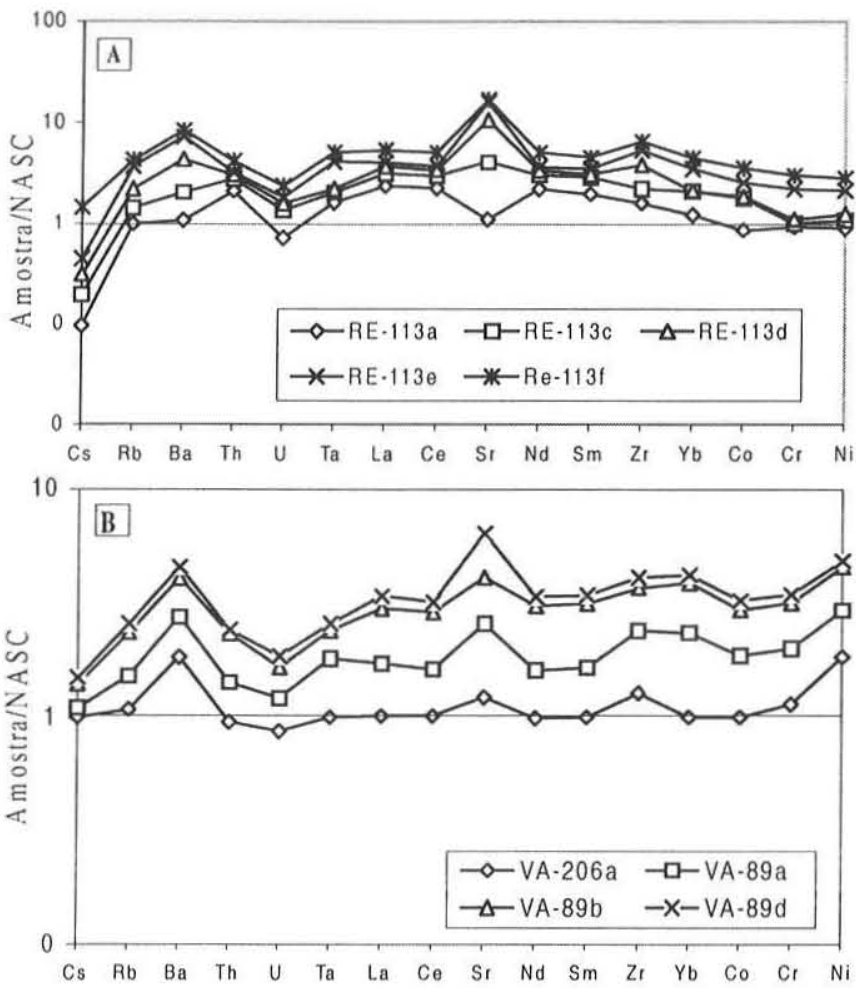

Figura 5 - Diagramas multielementares. A. Três Pontas; B. Varginha.

uma direção que vai do ponto de composição final do plagioclásio ao segmento da illita, sugerindo um trend de alteração no qual a maior parte das rochas é caracterizada por um modesto grau de intemperismo. Embora os valores médios de IAQ possam sugerir uma maior atuação de intemperismo químico na área-fonte dos cianita gnaisses Três Pontas, o diagrama mostra que as amostras com os maiores valores de IAQ, assim como os xistos e quartzitos das outras unidades, dispõem-se ao longo de um trend aproximadamente paralelo ao eixo A-K, o que pode caracterizar perdas significativas de $\mathrm{K}_{2} \mathrm{O}$ causadas por alteração avançada. De qualquer modo, este fato parece refletir uma grande

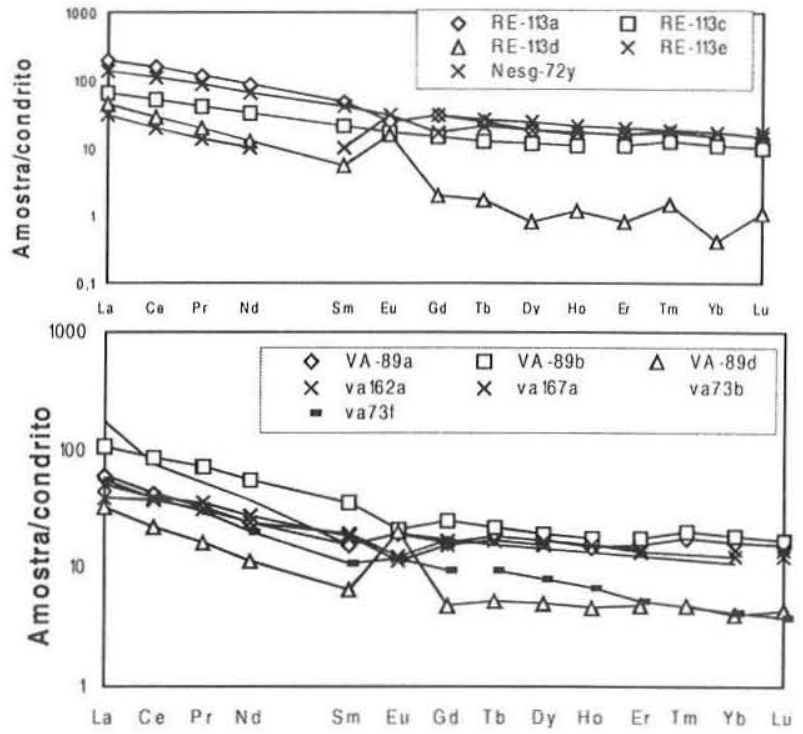

Figura 6-Diagramas de elementos terras raras. A. Três Pontas; B. Varginha.

heterogeneidade na fonte destes metassedimentos ou, alternativamente, modificações localizadas produzidas por alterações hidrotermais, além do intemperismo. Segundo Nesbitt \& Young $(1982,1984)$, os valores do IAQ podem ser considerados relativamente imutáveis mesmo sob metamorfismo de alto grau.

Outro elemento importante na identificação do intemperismo são as razões $\mathrm{Rb} / \mathrm{Sr}$. Valores inferiores a 1, como a maioria dos observados, em geral refletem histórias de intemperismo pouco significativas. Estas razões tendem a aumentar com o aumento do IAQ, fato consistente com esta afirmação.

Discussão A composição química dos metassedimentos analisados mostra uma significativa variação química que reflete provavelmente suas histórias de sedimentação e intemperismo. Entre os cianita e cianita/sillimanita gnaisses da Nappe Três PontasVarginha, que consistem no grupo mais representativo deste estudo, observa-se, de um modo geral, dois tipos de comportamento 


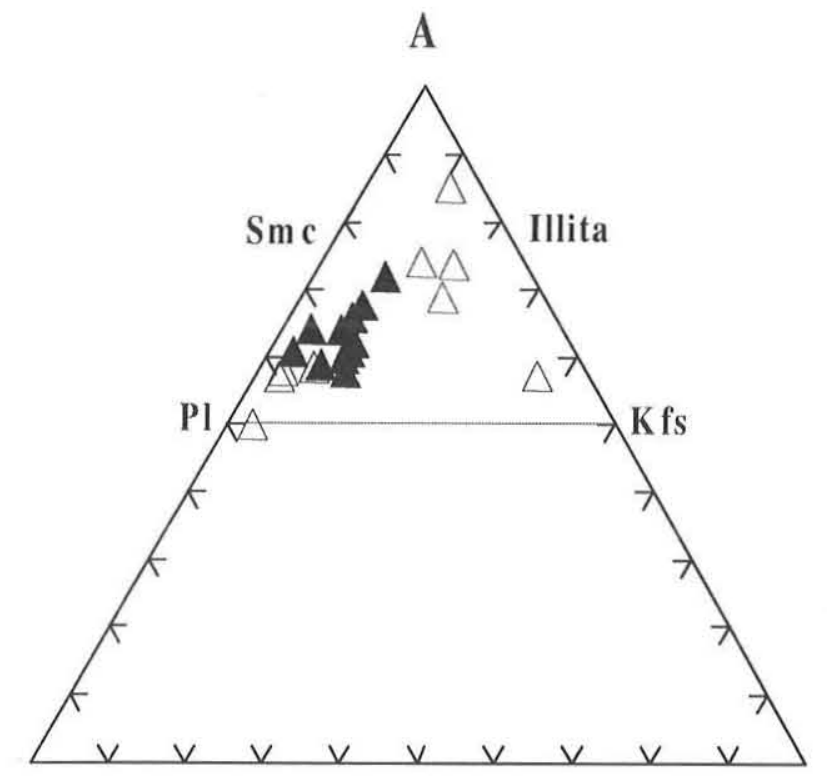

$\mathrm{CN}$

Figura 7-Diagrama A-CN-K. Triângulo vazado = Três Pontas; triângulo cheio $=$ Varginha .

químico, que são refletidos tanto nos elementos maiores como nos traços. Como regra geral, as amostras de Varginha apresentam maior homogeneidade química, enquanto que entre os gnaisses de Três Pontas os dados são mais dispersos.

Com base nas razões $\mathrm{SiO}_{2} / \mathrm{Al}_{2} \mathrm{O}_{3}$ e $\mathrm{K}_{2} \mathrm{O} / \mathrm{Na}_{2} \mathrm{O}$, as amostras foram separadas em dois grupos caracterizados por sedimentos com afinidades distintas. A totalidade das amostras de Varginha e parte das amostras de Três Pontas exibe razões $\mathrm{K}_{2} \mathrm{O} / \mathrm{Na}_{2} \mathrm{O}$ baixas (= 2), compatíveis com sedimentos psamíticos com grande proporção de feldspatos, possivelmente wackes, ou arenitos feldspáticos. Condie et al. (1991) alertam que a razão $\mathrm{K}_{2} \mathrm{O} / \mathrm{Na}_{2} \mathrm{O}$ pode sofrer decréscimos devido à perda de $\mathrm{K}$ durante o metamorfismo de alto grau. Porém, tais perdas representariam também um aumento nos valores de IAQ, o que não ocorre com as rochas de Varginha e parte das de Três Pontas que apresentam baixas razões $\mathrm{K} / \mathrm{Na}$ (IAQ=48-67). Este fato indica que as razões obtidas refletem a composição original dos sedimentos envolvidos. Outro grupo de amostras de Três Pontas apresenta razões $\mathrm{K}_{2} \mathrm{O} / \mathrm{Na}_{2} \mathrm{O}$ altas $(>4)$ que são compatíveis com uma origem a partir de sedimentos pelíticos. Este comportamento é consistente com as observações de Janasi (1999) que, com base nos índices A/CNK e N/K, reúne amostras semelhantes em dois grupos caracterizados, respectivamente, por altas razões $\mathrm{N} / \mathrm{K}(>1)$, denominados pelo autor de metagrauvacas, e por razões $N / K$ baixas $(<0,4)$ e A/CNK bastante altas $(>3)$, que corresponderiam a metapelitos.

Três tipos de padrões de ETR foram reconhecidos nas rochas estudadas. O mais freqüente é caracterizado por enriquecimento em ETRL, distribuição plana dos ETRP e relativa anomalia negativa de Eu, sendo, no geral, indistinguível daqueles encontrados nas médias de folhelhos pós-arqueanos mais comuns, como PAAS (post-Archean Australian Shales - Nance \& Taylor 1976) e NASC (North American Shale Composite-Gromet et al. 1984). Anomalias negativas de Eu indicam que processos de diferenciação crustal envolvendo a separação de plagioclásio do líquido residual, como fusão parcial ou cristalização fracionada, afetaram substancialmente as rochas na área-fonte. Taylor \& McLennan (1985) e McLennan et al. (1991, 1995) ponderam que processos deste tipo foram pouco significativos durante o Arqueano, mas tornaram-se dominantes a partir da transição para o pós-Arqueano devido à cratonização generalizada que parece ter se estabelecido no Neoarqueano. Valores de IAQ bastante altos (79), para gnaisses tipo-Três Pontas (RE113a) são sugestivos de uma proveniência a partir de fonte antiga e de uma história de intemperismo mais longa. McLennan et al. (1991) reportaram características semelhantes em rochas do arco continental de Java, interpretadas como indicativas de contribuição variável de crosta continental antiga (tanto por erosão de rochas ígneas ou metamórficas ou por reciclagem de rochas sedimentares) no ambiente de arco moderno. Uma origem por aporte fluvial de área fonte mais antiga, extra-arco, também foi aventada por aqueles autores. Uma considerável diversidade nos padrões de ETR foi identificada por McLennan \& Taylor (1991) para turbiditos modernos formados em diferentes ambientes de margens ativas e resultando da interação entre vários componentes de proveniência. Resultados semelhantes foram indicados pelos dados de Janasi (1999) e Janasi et al. (2000).

Outro padrão de ETR caracteriza-se, como o anterior, pela disposição quase plana dos ETRP, mas com significativo empobrecimento em ETRL, acompanhado por anomalias positivas de Eu. Tal comportamento, especialmente as anomalias positivas de Eu, não parece ser compatível com nenhum dos padrões mais comuns já reportados para rochas sedimentares, sugerindo a participação de processos posteriores à geração dos sedimentos. Adicionalmente, o extremo fracionamento observado na amostra RE113d $\left(\mathrm{La}_{\mathrm{N}} / \mathrm{Yb}_{\mathrm{N}}=109\right)$ deve resultar de modificações póssedimentares. Em muitos locais, as temperaturas atingidas pelo metamorfismo foram extremamente elevadas $\left(>900^{\circ} \mathrm{C}\right.$, Campos Neto \& Caby 2000), e responsáveis por bandas de leucossoma a feldspato potássico. A amostra RE113d, apresenta, com efeito, uma grande proporção de microclina modal, o que explica a forte anomalia positiva observada neste espécime. Acredita-se que esta amostra resulte de líquido anatético extraído de rocha rica em granada, o que explicaria o intenso fracionamento verificado no padrão. É possível que, ao menos em parte, as outras amostras, que apresentam padrões não tão extremos, representem produtos intermediários entre metassedimentos e fusão granítica anidra.

Conclusões As amostras examinadas neste estudo mostram uma considerável diversidade química que provavelmente reflete, em boa parte, a heterogeneidade de suas fontes. Com base nos dados obtidos, foi possível estabelecer diversas diferenças e semelhanças entre os gnaisses tipo Varginha e Três Pontas.

Os cianita/sillimanita gnaisses tipo-Varginha apresentam uma variação composicional relativamente pequena, com razões $\mathrm{SiO}_{2}$ / $\mathrm{Al}_{2} \mathrm{O}_{3}$ altas $(3,03-4,59)$ e $\mathrm{K}_{2} \mathrm{O} / \mathrm{Na}_{2} \mathrm{O}$ relativamente baixas $(0,23-2,48)$ e que sugerem uma origem a partir de sedimentos psamíticos ricos em feldspato, provavelmente wackes. Os baixos valores de IAQ (51-65) indicam que as rochas na área-fonte sofreram histórias intempéricas pouco severas, marcadas por predomínio de intemperismo físico ou por processo intempéricos de curta duração. Estas características poderiam ser esperadas em um ambiente de clima frio, como já aventado na região por Ribeiro et al. (1995). No cntanto, se aliadas aos resultados isotópicos (Sm-Nd T(DM) 1,4-1,6 Ga com valores de $\varepsilon_{\mathrm{Nd}}(\mathrm{T}=625 \mathrm{Ma})$ até próximo de zero; Janasi 1999), apontam para ambientes orogênicos, próximos a arcos magmáticos. 
Os cianita gnaisses do tipo Três Pontas podem ser, composicionalmente, agrupados em dois conjuntos com características químicas distintas, o que indica a contribuição de diferentes componentes na proveniência dos sedimentos. O primeiro conjunto, com razões $\mathrm{SiO}_{2} / \mathrm{Al}_{2} \mathrm{O}_{3}$ altas e pouco variadas $(3,28$ $4,69)$, além de baixo $\mathrm{K}_{2} \mathrm{O} / \mathrm{Na}_{2} \mathrm{O}(0,45-1,06)$ e de valores IAQ $(48-60)$, aproxima-se das rochas tipo-Varginha. $\mathrm{O}$ segundo conjunto apresenta razões $\mathrm{SiO}_{2} / \mathrm{Al}_{2} \mathrm{O}_{3}$ altas e variadas $(2,55-4,71)$ e altas razões $\mathrm{K}_{2} \mathrm{O} / \mathrm{Na}_{2} \mathrm{O}(2,30-11,71)$, constituindo prováveis produtos de sedimentos pelíticos relativamente puros. Os valores de IAQ são altos (67-79) e sugestivos de histórias intempéricas prolongadas e marcadas por intemperismo químico. Fontes crustais antigas e deposição controlada por períodos tectonicamente estáveis, são os mais prováveis para a origem destes sedimentos. Os cenários prováveis para a deposição destas rochas poderiam admitir:

- uma bacia de ante-arco, alternando períodos de grande atividade orogênica no arco, com períodos tectonicamente estáveis;

- deposição na placa continental em subducção (Sanfrancisca), já próxima e portanto penecontemporânea a colisão com a margem ativa, misturando sedimentos provenientes do arco com sedimentos provenientes da margem passiva.

Agradecimentos Os trabalhos de pesquisa foram financiados pela FAPESP, processos 97/07682-5 e 98/15624-8. Aos revisores da RBG pelas sugestões ao manuscrito.

\section{Referências}

Campos Neto M.C. \& Figueiredo M.C.H. 1995. The Rio Doce Orogeny, Southeastern Brazil. J. South Am. Earth Sci., 8:143162.

Campos Neto M.C., Caby R. 1999. Neoproterozoic high-pressure metamorphism and tectonic constraint from the nappe system south of São Francisco Craton, southeast Brazil. Prec. Res., 97:3-26.

Campos Neto M.C., Caby R., Janasi V.A., Basei M.A.S., Garcia M.G.M., Siga Jr. O. 1999 Transition from continental to intracontinental subduction, south of São Francisco Cráton: terrane accretion, metamorphic paths and nappe kinematics. In: SBG, SNET, 7, Anais, 66-69.

Campos Neto M.C. \& Caby R. 2000. Terrane accretion and upward extrusion of high-pressure granulites in the Neoproterozoic nappes of southeast Brazil: petrologic and structural constraints. Tectonics 19:669-687.

Campos Neto M.C., Basei M.A.S., Vlach S.R.F., Caby R., Szabó A.J., Vasconcellos P. (inédito) Migração de orógenos e superposição de orogêneses: um esboço da colagem Brasiliana no sul do Cráton do São Francisco, SE-Brasil. Geologia USP (aceito para publicação).

Chrispin S.J. 1990. Mapeamento geológico de uma área na folha Carmo da Cachoeira (MG) com ênfase na geologia estrutural das serras da Bocaina e do Faria. Dissertação de Mestrado, IG/UFRJ, 171pp (inédito).

Condie K.C., Wilks M., Rosen D.M.,Zlobin V.L. 1991. Geochemistry of metasediments from the Precambrian Hapschan Series, eastern Anabar Shield, Siberia. Prec. Res., 50:37-47.

Garcia M.G.M., Campos Neto M.C., Fallick A.E. (2003) Oxygen isotope composition and thermometry of high- to low-grade metasedimentary rocks: a study from the Neoproterozoic collision-related nappe system south of São Francisco Craton, SE Brazil. J. South Am. Earth Sci., 15:871-883.

Gromet L.P., Dymek R.F., Haskin L.A., Korotev R.L. 1984. The "North American Shale Composite": its compilation, major and trace element characteristics. Geoch. Cosmoch. Acta, 48:2469-2482.

Heilbron M., Gonçalves M.L, Teixeira W., Trouw R.A.J., Padilha A.V., Kawashita K. 1989. Geocronologia da Região entre Lavras, São João del Rei, Lima Duarte e Caxambu (MG). Anais daAcad. Bras. Ciênc., 61:177-199.

Janasi V.A. 1999. Petrogênese de granitos crustais na Nappe de Empurrão Socorro-Guaxupé (SP-MG): uma contribuição da geoquímica elemental e isotópica. Tese de LivreDocência, IG/USP, 304p. (inédito)

Janasi V.A., Campos Neto M.C., Vasconcellos A.C., Van Schmus
W.R., Garcia M.G.M. 2000. Geochemical and isotopic (Nd, Sr) evidences for a Neoproterozoic juvenile component in metasediments from allochtonous terranes in the southern Brasília Belt, Brazil. In: International Geological Congress, 31 , Rio de Janeiro, RJ., Abstracts and CD-ROM.

Jost H., Theodoro S.M.C.H., Figueiredo A.M.G., Boaventura G.R. 1996. Propriedades geoquímicas e proveniência de rochas metassedimentares detríticas arqueanas dos greenstone belts de Crixás e Guarinos, Goiás. Rev. Bras. Geoc., 26:151-166

Machado N. \& Gauthier G. 1986. Determination of ${ }^{207} \mathrm{~Pb} /{ }^{206} \mathrm{~Pb}$ ages on zircon and monazite by laser-ablation ICPMS and application to a study of sedimentary provenance and metamorphism in southeastern Brazil. Geoch. Cosmoch. Acta, 60:5063-5073.

Maciel R.R. 1986. Mapeamento geológico-estrutural de uma área a leste da cidade de Três Pontas, MG. Dissertação de Mestrado, IG/UFRJ,102pp (inédito).

McLennan S.M. \& Taylor S.R. 1991. Sedimentary rocks and crustal evolution: tectonic setting and secular trends. J. Geol., 99:121.

Mc Lennan S.M., Taylor S.R., McCulloch M.T., Maynard J.B. 1990. Geochemical and Nd-Sr isotopic composition of deep-sea turbidites: Crustal evolution and plate tectonic associations. Geoch. Cosmoch. Acta 54:2015-2050.

Mc Lennan S.M., Hemming S.R., Taylor S.R., Eriksson K.A. 1995. Early Proterozoic crustal evolution: Geochemical and Nd-Pb isotopic evidence from metasedimentary rocks, southwestern North America. Geoch. Cosmoch. Acta, 59:1153-1177.

Nance W.B. \& Taylor S.R. 1976. Rare earth element patterns and crustal evolution - I. Australian post-Archean sedimentary rocks. Geoch. Cosmoch. Acta, 41:225-231.

Nesbitt H.W., Young G.M. 1982. Early Proterozoic climates and plate motions inferred from major chemistry of lutites. Nature 299:715-717.

Nesbitt H.W. \& Young G.M. 1984. Prediction of some weathering trends of plutonic rocks based on thermodynamic and kinetic considerations. Geoch. Cosmoch. Acta 48:1523-1534.

Ribeiro A., Trouw R.A.J., Andreis R.R., Paciullo F.V.P., Valença J, 1995. Evolução das bacias Proterozóicas e o termo-tectonismo Brasiliano na margem sul do cráton do São Francisco. Rev. Bras. Geoc., 25:235-248.

Rollinson H. 1993. Using Geochemical Data: evaluation, presentation, interpretation. Longman Scientific \& Technical, New York, 352pp.

Söllner F., Trouw RA.J. 1997. The Andrelândia Depositional Cycle 
(Minas Gerais/Brazil), a Post-Transamazonic sequence south of the São Francisco Craton: evidence from U-Pb dating on zircons of a metasediment. J. South Am. Earth Sci., 10:21-28.

Taylor S.R. \& McLennan S.M. 1981. The composition and evolution of the continental crust: rare earth element evidence from sedimentary rocks. Phil. Trans. R. Soc. A301:381-399.

Taylor S.R. \& McLennan S.M. 1985. The continental crust: its composition and evolution. Blackwell, Oxford.

Trouw R.A.J., Ribeiro A., Paciullo F.V.P. 1986. Contribuição a geologia da Folha Barbacena 1:250.000. In: SBG, Cong. Bras. Geol., 39, 2:974-984.

Trouw R.A.J. \& Castro E.M. 1996. Significado tectônico de granulitos Brasilianos de alta pressão no sul de Minas Gerais. In: SBG, Cong. Bras. Geol, 39, 6:145-148.

Trouw R.A.J.,PaciulloF.V.P., Ribeiro A. 1998. Tectonic significance of Neoproterozoic high pressure granulites in southern Minas Gerais. In: International Conference on Basement Tectonics, 14, Abstracts: 69-71.
Trouw R.A.J., Heilbron M., Ribeiro A., Paciullo F.V.P, Valeriano C.M., Almeida J.C.H., Tupinambá M. e Andreis R.R. 2000. The central segment of the Ribeira Belt. In: U.G. Cordani, E.J. Milani, A. Thomaz Filho, D.A. Campos (Edits.): Tectonic Evolution of South America, 31 International Geological Congres, pp. 287-310.

Valladares C., Machado N., Heilbron M., Tupinambá M., Duarte B., Gauthier G., Noronha M. 1999. Ages of detrital zircon from central Ribeira Belt (Brazil) using Laser-Ablation-ICPMS. Boletim Geol. Minero Argentino 34:145-147.

Wronkiewicz D.J. \& Condie K.C. 1987. Geochemistry of sediments from the Pongola Supergroup, South Africa: evidence for a 3Ga-old evolved continental craton. Geoch. Cosmoch. Acta 53:1537-1549.

Manuscrito A-1377

Recebido em 27 de setembro de 2002 Revisão dos autores em15 de novembro de 2003 Revisão aceita em 25 de novembro de 2003 